\title{
STUDY ON REINFORCEMENT OF FABRICATED HOLLOW SLAB BRIDGE BY POLYURETHANE-CEMENT COMPOSITE (PUC)
}

\author{
Zhang Kexin', Qi Tianyu1, Zhu Zhimin², Xue Xingwei1 ,Shen Xinyuan'1 \\ 1. School of Traffic Engineering, Shenyang Jianzhu University, Shenyang, \\ 110168,PR of China; jt_zkx@sjzu.edu.cn \\ 2. Liaoning Urban Construction Design Institute Co. LTD, Shenyang, 110000, PR \\ of China
}

\begin{abstract}
In this paper, a new polyurethane-cement composite (PUC) material is used to reinforce a 25-year hollow slab bridge. PUC material is composed of polyurethane and cement, which has good mechanical properties. After pouring PUC material at the bottom of the hollow slabs, the traffic can be restored in a short time. Ultimate bearing capacity was discussed based on the concrete structures. The bending failure mode of concrete reinforced T-beam bridges strengthened with PUC was controlled through PUC design strength. The main construction process was introduced, including concrete surface treatment, supporting template and pouring. To investigate the effectiveness of PUC in strengthening bridges, load tests were conducted before and after the reinforcement. The test results showed that PUC possibly removed the bridge load and increase the stiffness of the hollow slabs. The maximum carrying capacity and stiffness of the main girder were increased by about $20 \%$ and $28 \%$ after PUC material was poured. Meanwhile, the width of the cracks was reduced in different degrees.
\end{abstract}

\section{KEYWORDS}

Polyurethane-cement composite (PUC), Strengthening, Hollow slab, Strength analysis, Field application, Load test

\section{INTRODUCTION}

Concrete bridges are uninterruptedly unprotected to external environments. During their life spans, concrete bridges frequently experience situations that cannot be predicted during design. The durability of a concrete bridge is reduced by construction defects, overloaded vehicles, material characteristics, and environmental variations [1,2]. Replacing bridges to improve bridge performance can cause economic loss and inconvenient vehicle traffic [3]. Many researchers have studied proper repair and strengthening methods to solve the problems that occur in concrete structures $[4,5]$.

To improve the working ability of concrete bridges, many techniques have been used in strengthening. The most common methods for strengthening beams have been the use of Carbon Fibre Reinforced Polymer (CFRP), steel plate bonding, high strength wire mesh reinforcement and others; these methods are widely used at present [6]. CFRP has good performance, high strength and light weight, but there are some disadvantages of CFRP reinforcement, the most important is 
the high cost of CFRP reinforcement [7,8]. Bonding steel plates have the disadvantages of weakened bonding caused by steel corrosion, increased dead load weight and difficulties in adapting to the concrete surface profile $[9,10]$. High-strength steel wire mesh has the advantages of convenient construction and small section size [4]. Usually, high-strength steel strand is bonded and anchored to the main beam concrete by mortar or composite mortar, but mortar or composite mortar has low adhesion, which is prone to the peeling and destruction of the reinforcement layer and the main beam, leading to the de-crease of material utilization [11-12].

The introduction of new construction materials such as polyurethane-cement composite (PUC) to civil engineering can provide a potential solution. PUC is a polymer material made from a mixture of polyurethane raw materials and cement [13-15]. Polyurethane (PU) is a high performance polymer elastic material mainly based on the chemical compounds of polyisocyanate and polyester polyol. PUC has the advantages of light quality, significant strength in compressive and blending strength $[13,14]$. PUC has excellent bonding and adhesive properties with concrete materials, and it does not need additional adhesive for beam reinforcing [15].

PUC has been successfully used in strengthening T-beam girders, as proven through comprehensive laboratory tests. Haleem reported 10 beams strengthened with PUC under different load conditions, and the results showed a significant improvement of beam -bearing capacity. An experimental study on strengthening reinforced concrete T-beams using PUC [15]. The increment values of compressive strength were from $5 \mathrm{MPa}$ to $60 \mathrm{MPa}$ of PUC with density $400 \mathrm{~kg} / \mathrm{m}^{3}$ density and $1650 \mathrm{~kg} / \mathrm{m}^{3}$ respectively, while the flexural tensile strength was increased from 3.3 MPa to $44.3 \mathrm{MPa}$ of PUC with $400 \mathrm{~kg} / \mathrm{m}^{3}$ and $1650 \mathrm{~kg} / \mathrm{m}^{3}$ density respectively indicating highly improvement in compressive and bending tensile strength compare with conventional concrete [14]. Nevertheless, these research projects were performed with laboratory-scale tests and corresponding analyses. Applying and obtaining the application results in engineering are essential.

The cross section of the plate made hollow is called hollow plate. The hollow slab bridge is composed of a number of hollow slabs connected horizontally. The hollow slab is lighter than the solid slab of the same span, convenient for transportation and installation, and the building height is smaller than the T beam of the same span, so it is used more in the small span bridge. This study describes PUC as a material used to strengthen a 25-year-old fabricated reinforced concrete hollow slab bridge, including design, field application, field test and analysis.

\section{ANALYSIS AND DESIGN}

\section{Bridge description}

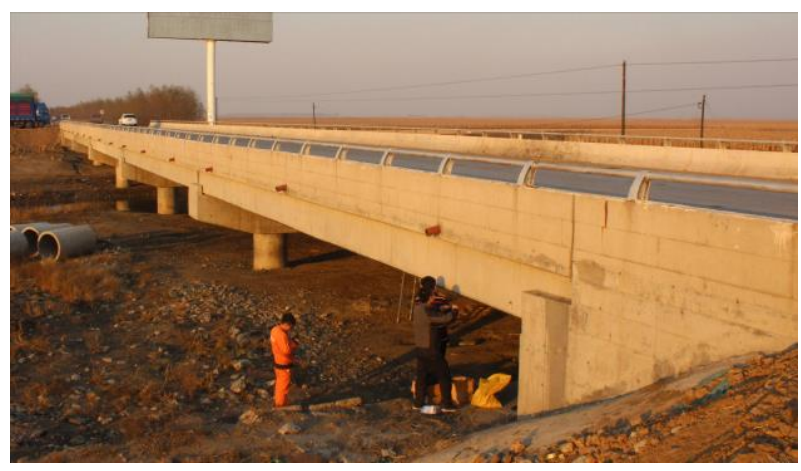

Fig. 1 - Lateral view of Piao Fa Bridge 


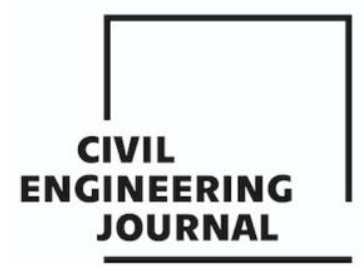

Article no. 29

THE CIVIL ENGINEERING JOURNAL 2-2021

Figure 1 shows a lateral view of Piao Fa Bridge. The bridge was built in 1995 and carries an average daily traffic of 800 vehicles. The bridge has 5 spans, each span being 20 meters of simply supported hollow slabs. Central supports consist of reinforced concrete bents, each supported by two circular columns. The total width is $12.0 \mathrm{~m}$, and the width of the driveway is $11.0 \mathrm{~m}$. The bridge has two lanes and carries one lane of traffic in each direction. The cross section of the superstructure consists of 9 hollow slabs with a width of $1.25 \mathrm{~m}$ Figure 2.

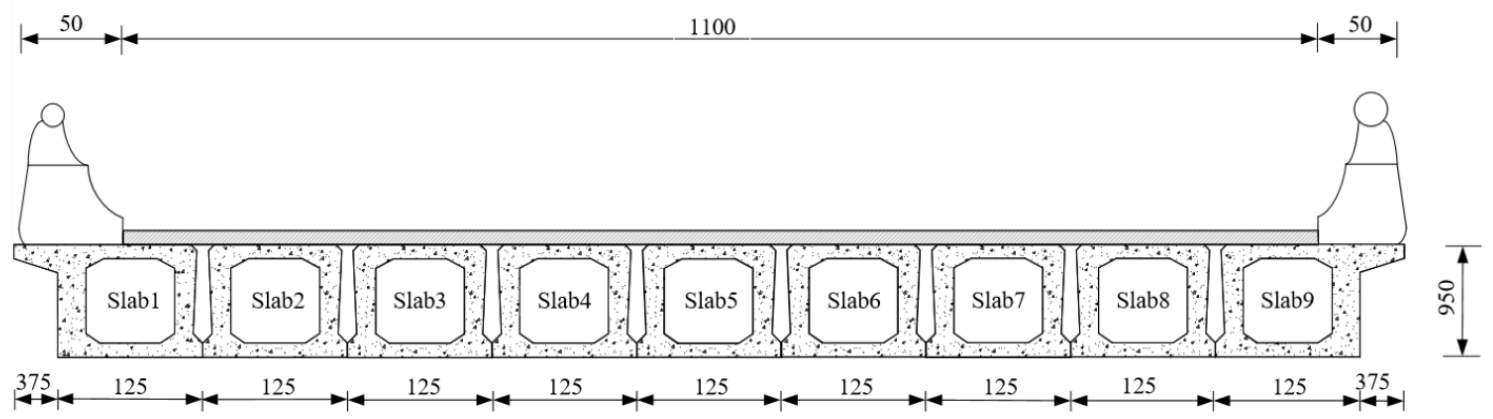

Fig. 2 - Cross-section of the bridge

The bridge has different degrees of damage caused by aging, overload, surging traffic and environment. During routine inspection, salt infiltration was observed in the bridge superstructure. Many hollow plates have the phenomenon of alkali spreading. Many vertical cracks appear on the bottom of the hollow slabs across the middle area. Serious cracks occurred in the edge-beam, as water from the pavement cracks affected the durability of the girder. Reinforcing the structure was selected because the owner did not agree to replace the bridge or limiting traffic. PUC strengthening method was chosen based on its application of being the least intrusive with traffic and being the most practical.

\section{MATERIAL CHARACTERISTICS}

This project adopts polyurethane cement material with good mechanical properties with a density of $1500 \mathrm{~kg} / \mathrm{m}^{3}$ to strengthen the hollow plate. The bending stress-strain curves of PUC with the same density are approximately the same. Bending test for PUC material is shown in Figure 3. The density of PUC mixed in the construction site was $1,524 \mathrm{~kg} / \mathrm{m}^{3}$. The bending stress-strain curves of five groups of stirred PUC specimens at the construction site are shown in Figure 4. Ultimate strength $\left(f_{\mathrm{Pu}}\right)$ was about $42.3 \mathrm{MPa}$. Design strength $\left(f_{\mathrm{Pu}}\right)$ was designed to be $3 / 4$ of the ultimate strength, and the corresponding strain was 0.006 under the design strength. The minimum modulus of elasticity ( $E_{\mathrm{Pd}}$ ) was $5 \mathrm{MPa}$. Table 1 shows the properties of PUC.

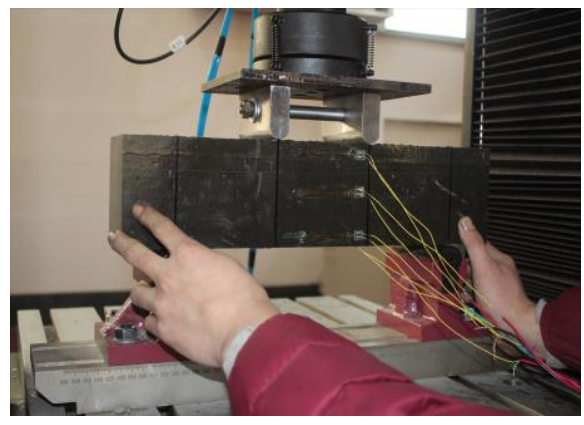

Fig. 3 - Bending test for PUC material 


\section{CIVIL}

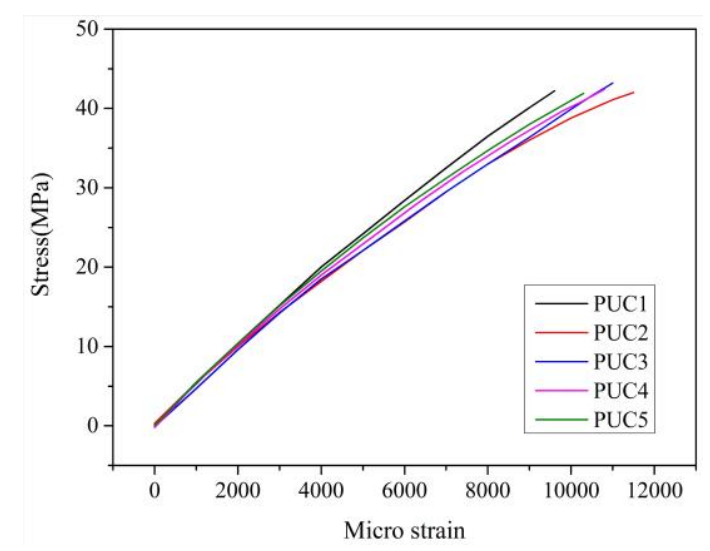

Fig. 4 - Blending stress-strain curve of the PUC

Basic properties such as the concrete compression strength and steel yield strength were assumed because the owner of the bridge did not allow coring to obtain the on-site strengths of the materials from the bridge girder. These basic properties $f_{\mathrm{c}} f_{\mathrm{s}}$ were assumed as described by JTJ023-85 [16] for bridges of that age because no sample could be obtained onsite. The parameters of steel strand refer to the standard drawing of the same span in the same year. The strength and elastic modulus of materials such as steel bar, strand, concrete and PUC are shown in Table 1.

Tab. 1 - Material properties

\begin{tabular}{|c|c|c|}
\hline Material & Property & Value \\
\hline \multirow{3}{*}{ PUC } & $f_{\mathrm{Pu}}(\mathrm{MPa})$ & 42.3 \\
\cline { 2 - 3 } & $f_{\mathrm{Pd}}(\mathrm{MPa})$ & 31.7 \\
\cline { 2 - 3 } & $E_{\mathrm{Pd}}(\mathrm{GPa})$ & 5.0 \\
\hline \multirow{3}{*}{ Concrete } & $f_{\mathrm{c}}(\mathrm{MPa})$ & 30 \\
\cline { 2 - 3 } & $E_{\mathrm{c}}(\mathrm{GPa})$ & 30 \\
\hline \multirow{3}{*}{ Steel } & $f_{\mathrm{s}}(\mathrm{MPa})$ & 335 \\
\cline { 2 - 3 } & $E_{\mathrm{s}}(\mathrm{GPa})$ & 200 \\
\hline
\end{tabular}

\section{STRENGTHEN ANALYSIS}

The service capacity of the inspected bridge is insufficient due to cracks, rain erosion and so on. Moreover, the owner of the bridge asked to complete the strengthening work with minimum interference to traffic. Therefore, the PUC material is designed to reinforce the hollow slab bridge. The hollow slab blending bearing capacity was analysed through the assumption that the plane section remained to be planar until failure. Blending bearing capacity was evaluated based on force equilibrium and strain compatibility until failure Figure 5.

The failure of the prestressed hollow slab strengthened with PUC material was slab bending failure because of the strong bonding performance between PUC material and concrete. The flexural capacity of the PUC -reinforced member depended on the concrete crushing or the PUC 
material's design strength. Two kinds of failure modes exist for PUC -strengthened the prestressed hollow slab according to Fig. (5) and plane assumption.

According to strain compatibility, the strain of steel bar ${ }^{\varepsilon_{\mathrm{s}}}$ can be expressed as follows.

$$
\varepsilon_{\mathrm{s}}=\frac{h_{\mathrm{s}}-x_{\mathrm{c}}}{h_{\mathrm{p}}-x_{\mathrm{c}}} \varepsilon_{\mathrm{p}}
$$

where $h_{s}$ represents the depth from the centroid of steel bars to the top of the T-cross section, $h_{\mathrm{P}}$ represents the depth from the centroid of the PUC section to the top of the hollow slab section, $x_{\mathrm{c}}$ represents the depth of the neutral axis and $\varepsilon_{\mathrm{p}}$ represents the strain of the centroid of the PUC section. When concrete crushing failed, the ultimate compressive strain for the concrete was assumed to be 0.003 , and the steel strand has been in a yield situation.

According to strain compatibility, the strain of the centroid of the PUC section ${ }^{\varepsilon_{\mathrm{p}}}$ can be expressed as follows.

$$
\varepsilon_{\mathrm{p}}=\frac{h_{\mathrm{p}}-x_{\mathrm{c}}}{x_{\mathrm{c}}} \varepsilon_{\mathrm{cu}}
$$

The PUC material and steel strand were treated as a nearly linear material, and the stress of the PUC material can be calculated by the following:

$$
\begin{gathered}
\sigma_{\mathrm{PUC}}=E_{\mathrm{PUC}} \varepsilon_{\mathrm{PUC}} \\
\sigma_{\mathrm{P}}=E_{\mathrm{P}} \varepsilon_{\mathrm{P}}
\end{gathered}
$$

The standard equilibrium equation is listed in Equation (5)

$$
\alpha_{1} f_{\mathrm{c}} b_{\mathrm{f}} x=f_{\mathrm{y}} A_{\mathrm{s}}+\sigma_{\mathrm{p}} A_{\mathrm{p}}+f_{\mathrm{PUC}} A_{\mathrm{PUC}}
$$

where $x=0.8 x_{c}, \alpha_{1}=1, A_{\mathrm{s}}$ represents the area of the steel bars, $f_{\mathrm{y}}$ represents the yield strain of the steel bars and $\varepsilon_{\mathrm{s}}$ represents the strain of the steel bars. $\varepsilon_{\mathrm{s}}$ can be calculated from a combination of equations (1) to (5), and $\varepsilon_{\mathrm{s}}$ goes beyond the allowance strain of steel rebars, which is 0.01 according to Design Code of Concrete Structures [17]. Therefore, beam failure is not controlled by concrete crushing failure.

The ultimate strain of PUC is about 0.006 when the strength of the PUC material is design strength. The steel bar strain is larger than the yield sign strain and less than 0.01 according to strain compatibility.

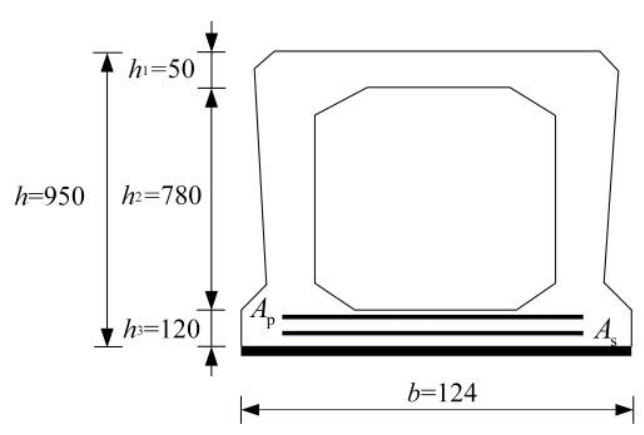

(a) Reinforced concrete section

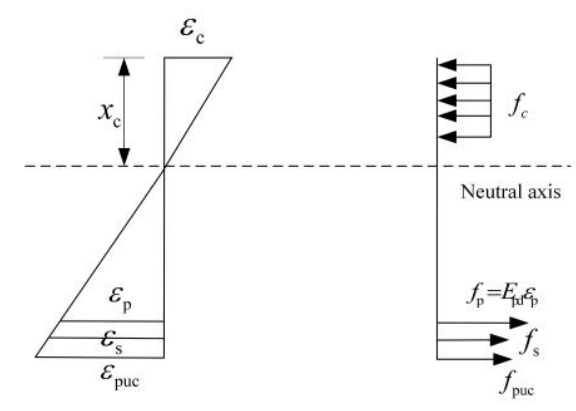

(b) Strain distribution

(c) Stress distribution

Fig. 5 - Internal strain and stress distribution for a hollow slab shape section 


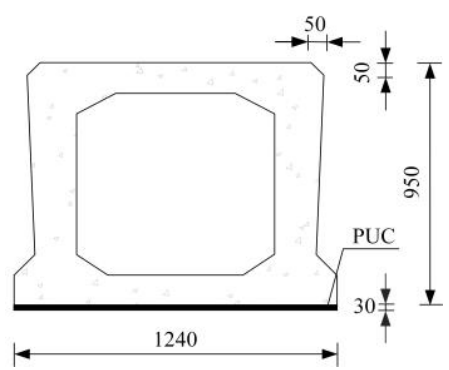

Fig. 6 - Hollow slab section strengthened with PUC material

$$
\begin{gathered}
\alpha_{1} f_{\mathrm{c}} b_{\mathrm{f}} x=f_{\mathrm{y}} A_{\mathrm{s}}+f_{\mathrm{P}} A_{\mathrm{P}}+f_{\mathrm{PUC}} A_{\mathrm{PUC}} \\
M_{\mathrm{u}}=f_{\mathrm{PUCd}} A_{\mathrm{PUC}}\left(h_{\mathrm{P}}-\frac{x}{2}\right)+f_{\mathrm{y}} A_{\mathrm{s}}\left(h_{\mathrm{s}}-\frac{x}{2}\right)+f_{\mathrm{Py}} A_{\mathrm{P}}\left(h_{\mathrm{s}}-\frac{x}{2}\right)
\end{gathered}
$$

where $A_{\mathrm{P}}$ represents the cross-sectional area of the PUC material, and $f_{\mathrm{Pd}}$ represents the design strength of the PUC material. The flexural strength of the beams after strengthening can be calculated through a combination of Equations (6) and (7).

The above mentioned analysis shows that the bearing capacity of the strengthened beam is controlled by the design strength of the PUC material. The flexural strength increased to 1543.7 kN.m through the pouring of the PUC material. The section of PUC is shown in Figure 6.

\section{STRENGTHENING PROCEDURE}

PUC strengthening is similar to the enlarging section method $[18,19]$, but the curing time of the PUC strengthening method is significantly less than the enlarging section method. First, degenerate materials are removed from the concrete surface, and the visible cracks in the surface of the girders are closed through a chemical method. Second, the concrete surface is chiselled to ensure that its roughness meets the China Construction Code of Concrete Structure. Loose materials, which affect the bonding performance of the PUC material, are removed through high pressure water washing.

In achieving a better bonding effect, sufficient time must be ensured to dry the concrete surface naturally. The construction templates were made depending on the design of the dimensions of the PUC material. The template was installed in the location specified Figure 8. The mixing ratio of the PUC components (polyol: polyisocyanate: cement) was 1:1:2 by weight. The mixed PUC material was poured into the templates. First, a water drill is used to form a round hole with a diameter of $40 \mathrm{~mm}$ at the hinge joint position. Then, at the deck location, the PUC material is dumped through the circular hole. The templates were removed after two hours Figure 7c.
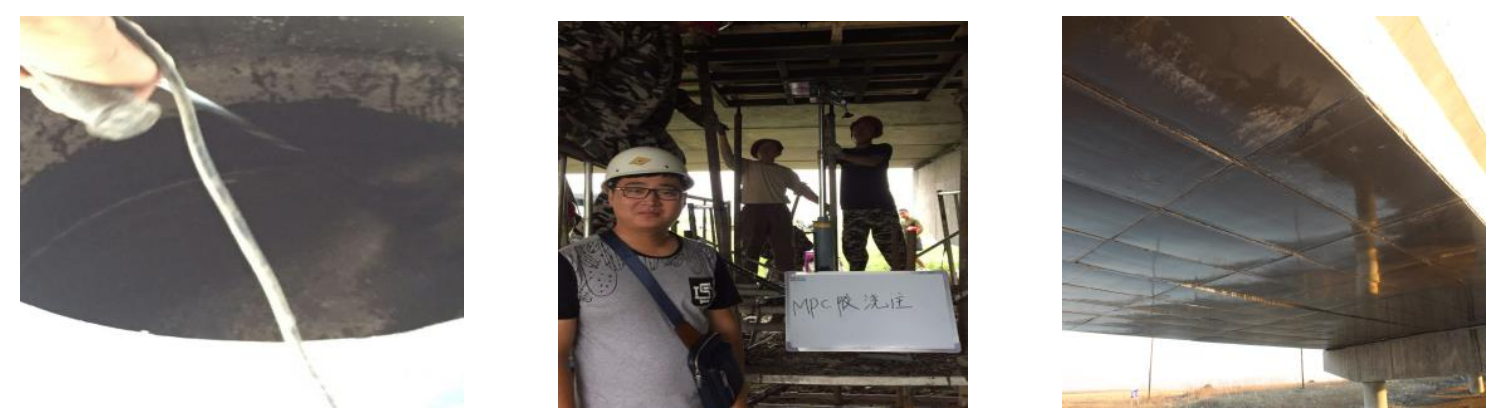

(a) Mixed the PUC material (b) Support formwork and PUC casting

(c) Template removal Fig. 7 - The PUC material casting 


\section{CIVIL}

\section{ENGINEERING} JOURNAL

\section{LOAD TEST}

Before strengthening and two months after strengthening, load tests were performed to obtain the service ability of the bridge. These tests are repeated once a year, and they will continue over a period of three years. Three-axle trucks are used as live load. The details of the trucks are shown in Figure 10. The gross rail loads before and after strengthening are listed in Table 2 . The bridge test was performed under four conditions. The two trucks were used at different locations for each condition and were assigned with unique letters $A$ and $B$.

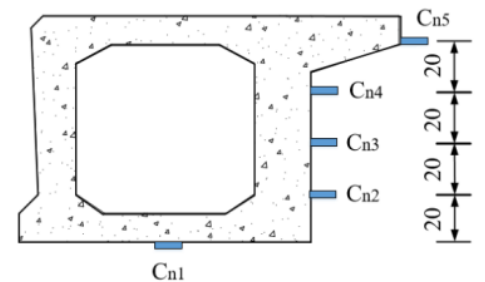

(a) Strain gages mounted oncConcrete

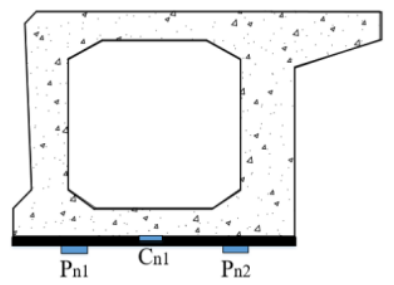

(b) Strain gages mounted on PUC

Fig. 9 - Locations of Strain Gages Mounted on the Slabs ( $n$ is the slab number

Tab. 2 -Gross axle load of trucks before and after strengthening

\begin{tabular}{|c|c|c|c|c|c|}
\hline \multicolumn{2}{|c|}{ Load-test trucks } & Force axle $t_{1}(\mathbf{k N})$ & Force axle $t_{2}(\mathbf{k N})$ & Back axle $t_{3}(\mathbf{k N})$ & Back axle $t_{4}(\mathbf{k N})$ \\
\hline \hline \multirow{2}{*}{ Before } & (A) & 79.5 & 79.3 & 157.4 & 157.4 \\
\cline { 2 - 6 } & (B) & 78.4 & 78.8 & 157.9 & 157.9 \\
\hline \multirow{2}{*}{ After } & (A) & 79.7 & 79.5 & 157.5 & 157.5 \\
\cline { 2 - 6 } & (B) & 79.7 & 79.9 & 157.6 & 157.6 \\
\hline
\end{tabular}
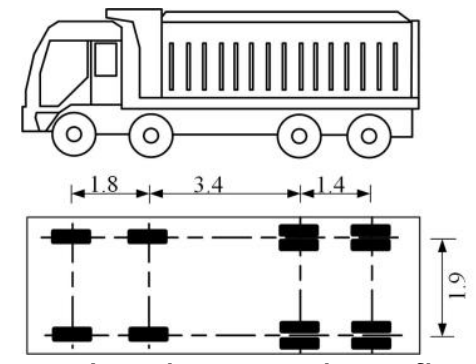

Fig. 10 - Load-test truck configuration

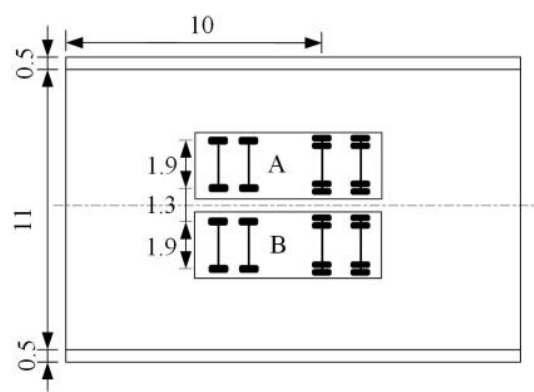

(a) Condition 1

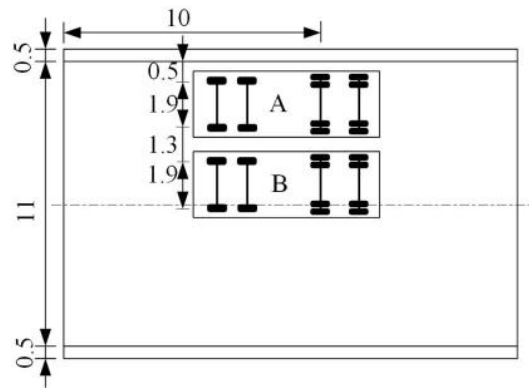

(b) Condition 2

Fig. 11 - Distribution of load-test trucks on the bridge deck at different 


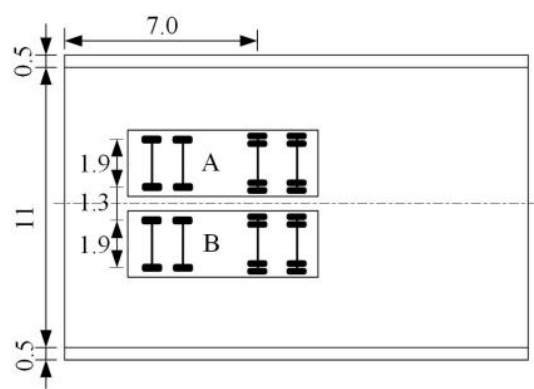

(c) Condition 3

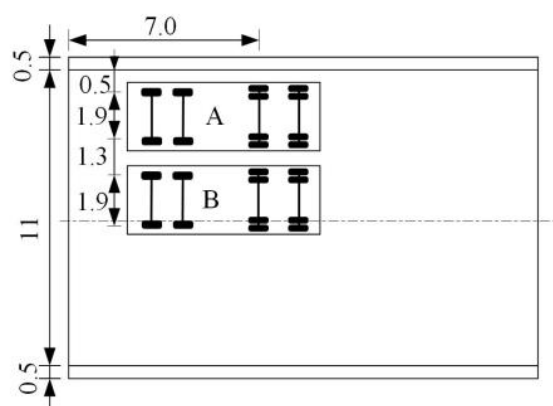

(d) Condition 4

Fig. 11 - Distribution of load-test trucks on the bridge deck at different

The testing of each condition was sequenced as follows: Truck A, Truck A + B, Truck B. The four conditions are shown in Figure 11. For condition 1, the two trucks were symmetrical with the centre of the bridge, and the distance from the outside wheels to the pavement edge was $2.95 \mathrm{~m}$. For condition 2, the two trucks deviated from the centre line of the bridge, and the distance from the outside wheels to the pavement edge was $0.5 \mathrm{~m}$. For both conditions 1 and conditions 2 , the third axle of the vehicles are in the middle of the span. For condition 3, the two trucks were symmetrical with the centre of the bridge, and the distance from the outside wheels to the pavement edge was $2.95 \mathrm{~m}$. For condition 4, the two trucks deviated from the centre line of the bridge, and the distance from the outside wheels to the pavement edge was $0.5 \mathrm{~m}$. For both conditions 3 and conditions 4, the four axles of the vehicles are in the middle of the span.

\section{STRAIN MEASUREMENT}

Strain gages were placed and arranged at the bottom of the mid-span, as shown in Figure 9a. The letter $n$ represents the hollow slab number, and the letter $C$ represents the concrete strain gages. Strain gauges $\left(\mathrm{C}_{n 1}\right)$ were installed on the bottom of the hollow slab before strengthening, as the bottom of the hollow slabs was covered with PUC after strengthening. The strain gages of the PUC surface are shown in Figure 9b. The letter $P$ represents the PUC strain gages. The gage $P_{n 2}$ and the gage $\mathrm{C}_{n 1}$ were installed at the same horizontal position. The strains were collected at a rate of two readings per second.

Figure 12 shows the concrete strain on the bottom concrete surface under live load in condition 1 before and after strengthening. The strain was the largest in the middle slab. The maximum strain of slab 5 were 75 microstrains for the two trucks (Trucks $A+B$ ) before strengthening because of the damage and the weak interaction between the slabs. After strengthening, the maximum strain of slab 5 were 60 microstrains for the two trucks (Trucks $A+B$ ). The maximum strains of hollow slab 3 were 50 microstrains and 45 microstrains before and after strengthening, respectively. The strain was reduced to about 5 microstrains. The maximum strains of slab 1 were 31 microstrains and 25 microstrains before and after strengthening, respectively. Therefore, the concrete strain can be reduced after the PUC material is poured. For condition 2 , the concrete strains on the bottom concrete surface under live load before and after strengthening are shown in Figure 12. The strain of beam 1 was the largest for the two trucks (Trucks $A+B$ ) because the two trucks approached the side of the bridge. The maximum strain of beam 1 were 88 microstrains before strengthening, and the strain became 69 microstrains after strengthening. Before strengthening, the strains of beam 3 and beam 5 were 83 and 76 microstrains, respectively, and after strengthening, the strains were 68 and 63 microstrains, respectively. In comparing the strains before and after strengthening, the concrete strain is reduced to some degree. 


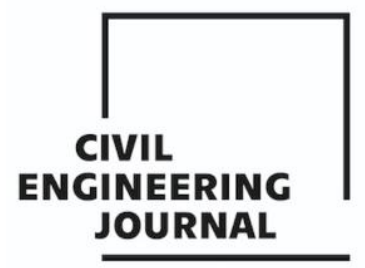

Article no. 2

THE CIVIL ENGINEERING JOURNAL 2-2021

Figure 13 shows the concrete strain on the bottom concrete surface under live load in condition 3 before and after strengthening. The strain was the largest in the middle slab. The maximum strain of slab 5 was 60 microstrains for the two trucks (Trucks $A+B$ ) before strengthening because of the damage and the weak interaction between the slabs. After strengthening, the maximum strain of slab 5 was 52 microstrains for the two trucks (Trucks $A+B$ ). The maximum strains of hollow slab 3 were 40 microstrains and 36 microstrains before and after strengthening, respectively. The strain was reduced to about 4 microstrains. The maximum strains of slab 1 were 25 microstrains and 20 microstrains before and after strengthening, respectively. Therefore, the concrete strain can be reduced after the PUC material is poured. For condition 4, the concrete strains on the bottom concrete surface under live load before and after strengthening are shown in Figure 13. The strain of beam 1 was the largest for the two trucks (Trucks $A+B$ ) because the two trucks approached the side of the bridge. The maximum strain of beam1 was 68 microstrains before strengthening, and the strain became 56 microstrains after strengthening. Before strengthening, the strains of beam 3 and beam 5 were 67 and 61 microstrains, respectively, and after strengthening, the strains were 56 and 52 microstrains, respectively. In comparing the strains before and after strengthening, the concrete strain is reduced to some degree.

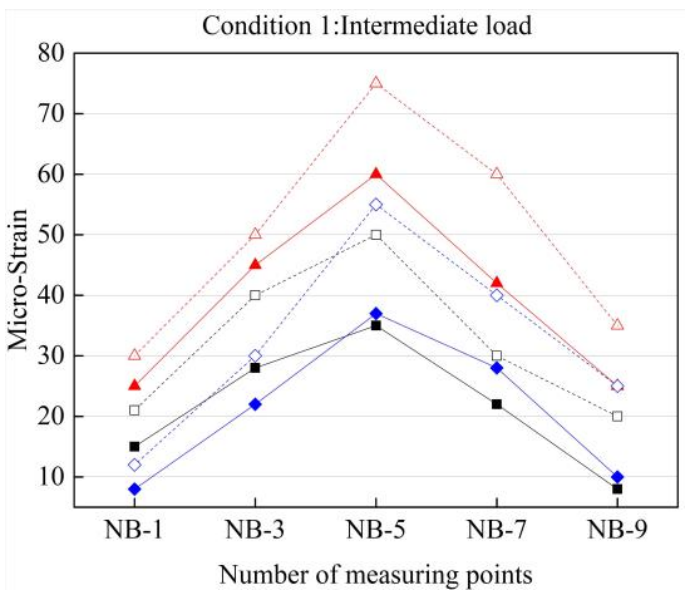

(a) Strains in the condition 1

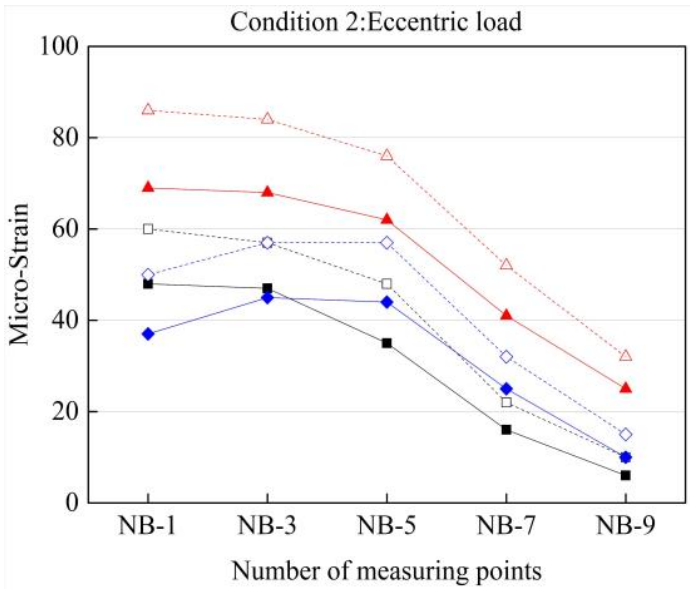

(b) Strains in the condition 1

\footnotetext{
10.0m-Before (Truck A )

- 10.0m-After (Truck A )

$-10.0 \mathrm{~m}$-Before (Truck A+B )

$\triangle 10.0 \mathrm{~m}-\mathrm{After}$ (Truck A+B )

$10.0 \mathrm{~m}$-Before (Truck B )

$-10.0 \mathrm{~m}-\mathrm{After}$ (Truck B )
}

(c) Annotation explanation

Fig. 12 - Recorded concrete strains of hollow slabs in condition 1 and condition 2 


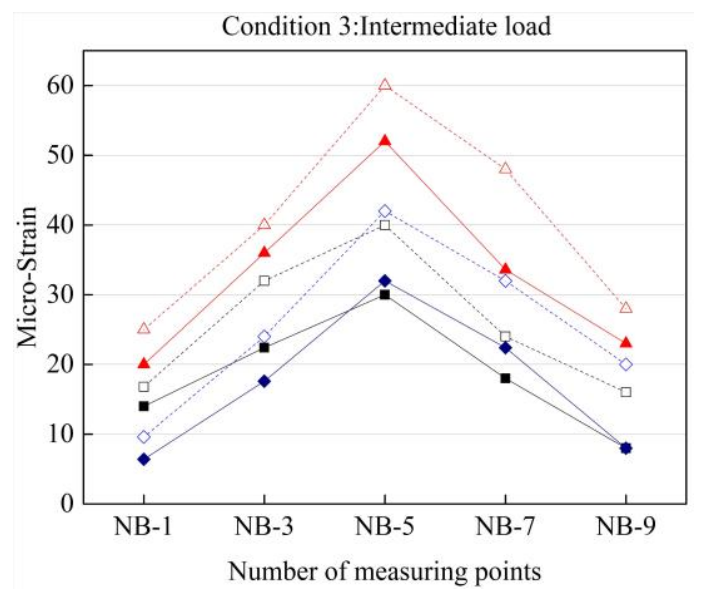

(a) Before strengthening

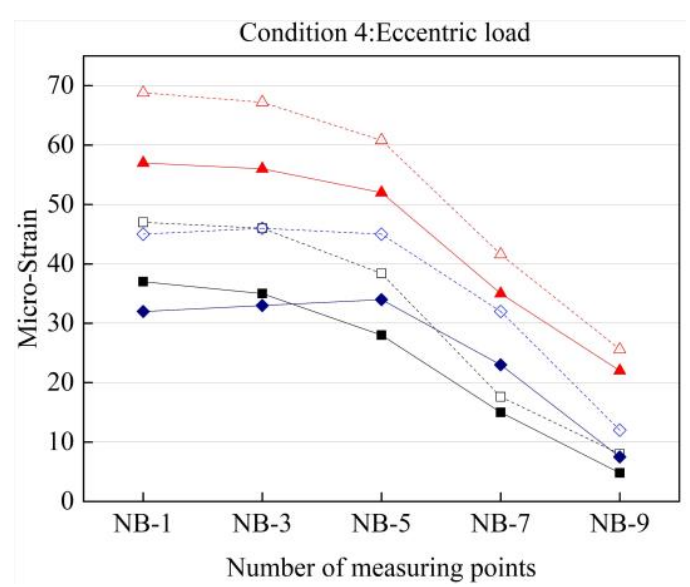

(b) After strengthening

$$
\begin{aligned}
& \quad \text { 7.0m-Before (Truck A ) } \\
& -7.0 \mathrm{~m}-\text { After (Truck A ) } \\
& -\quad 7.0 \mathrm{~m} \text {-Before (Truck A+B ) } \\
& \triangle \quad \text { 7.0m-After (Truck A+B ) } \\
& \diamond 7.0 \mathrm{~m} \text {-Before (Truck B ) } \\
& -7.0 \mathrm{~m}-\text { After (Truck B ) }
\end{aligned}
$$

(c) Annotation explanation

Fig. 13 - Recorded concrete strains in condition 2

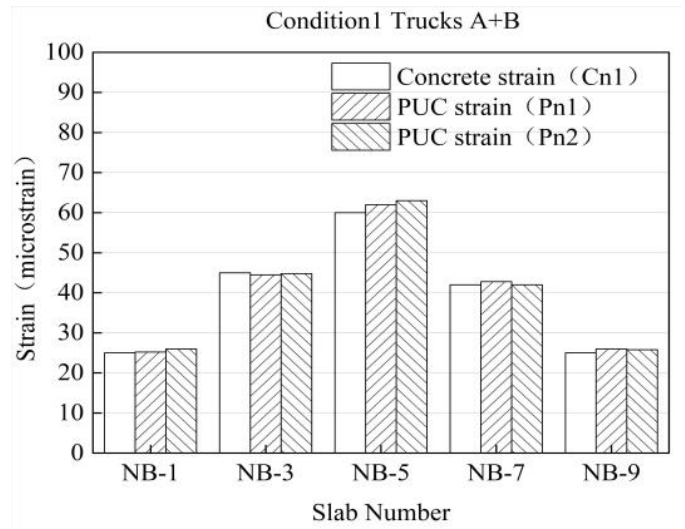

(a) Condition1 (Trucks $A+B$ )

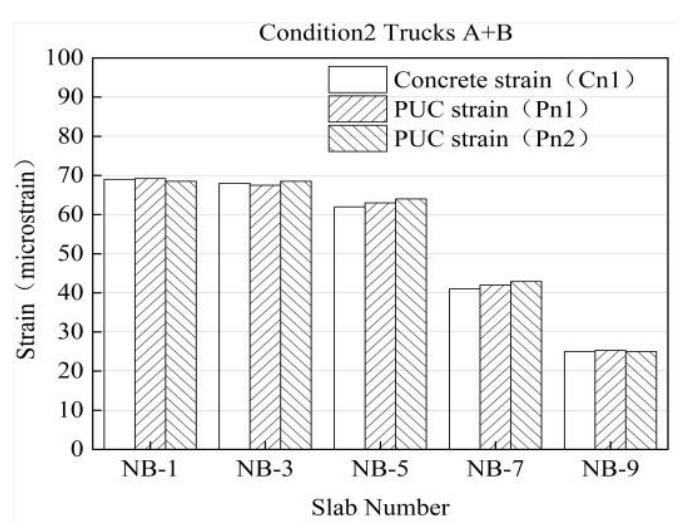

(b) Condition2 (Trucks $A+B$ )

Fig. 14 - Concrete Strains and PUC Strains at Different Positions

The recorded strain values of gages $\mathrm{C}_{n 1}, \mathrm{P}_{n 2}$ and $\mathrm{P}_{\mathrm{n} 1}$ for the five slabs in condition 1 and condition 2 are shown in Figure 14. In comparing the recorded concrete strains (gage $\mathrm{C}_{\mathrm{n} 1}$ ) and PUC strains (gage $P_{n 1}$ and gage $P_{n 2}$ ), the concrete strain values are close to the PUC strain values on the same horizontal height. Therefore, PUC strain compatibility is well at the live load. In comparing the PUC strains (gage $\mathrm{P}_{n 1}$ and gage $\mathrm{P}_{n 2}$ ) with those recorded on the concrete (gage $\mathrm{Cn}_{1}$ ), the PUC strains are approximately the same as that of concrete strains. Strain compatibility 


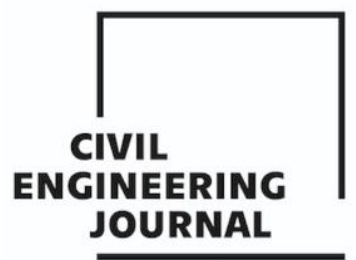

Article no. 2

THE CIVIL ENGINEERING JOURNAL 2-2021

leads to the higher PUC strain than the concrete strain because the bottom PUC is physically located below the bottom concrete in the beam section.

Measured concrete strains of slab 1 and slab 9 in the flange plate position are listed in Table 3. Two trucks (Trucks $A+B$ ) were parked on the bridge in the condition 1 and condition 2 . From this table, in comparing the strains for the given gages before and after pouring PUC, the compressive strains in the concrete were higher after the PUC was poured. In investigating this matter further, the axes were determined as shown in Table 4. Two trucks (Trucks A + B) were parked on the bridge in condition 1. From this table, as expected, the neutral axes of slab1 and slab5 migrated downwards by about $56 \mathrm{~mm}$ and $55 \mathrm{~mm}$, respectively, after the PUC was poured in condition1.

Tab. 3 - Measured compressive strain on slab 1 and slab 9

\begin{tabular}{|c|c|c|c|c|}
\hline \multirow{2}{*}{ Condition } & \multicolumn{2}{|c|}{ Gage C15 strain $(\mu \varepsilon)$} & \multicolumn{2}{c|}{ Gage C95 strain $(\mu \varepsilon)$} \\
\cline { 2 - 5 } & Before & After & Before & After \\
\hline \hline 1 & -19 & -21 & -18 & -20 \\
\hline 2 & -27 & -31 & -11 & -13 \\
\hline
\end{tabular}

Tab. 4 - Neutral axis investigation on condition 2

\begin{tabular}{|c|c|c|c|c|c|c|}
\hline \multirow{2}{*}{$\begin{array}{c}\text { Slab } \\
\text { number }\end{array}$} & \multicolumn{3}{|c|}{ Before strengthening $(\mu \varepsilon)$} & \multicolumn{3}{c|}{ After strengthening $(\mu \varepsilon)$} \\
\cline { 2 - 7 } & $\begin{array}{c}\text { Gage Cn1 } \\
\text { strain }(\mu \varepsilon)\end{array}$ & $\begin{array}{c}\text { Gage Cn5 } \\
\text { strain }(\mu \varepsilon)\end{array}$ & $\begin{array}{c}\text { Neutral axis } \\
\text { location }(\mathbf{m m} \\
)\end{array}$ & $\begin{array}{c}\text { Gage Cn1 } \\
\text { strain }(\mu \varepsilon)\end{array}$ & $\begin{array}{c}\text { Gage Cn5 } \\
\text { strain }(\mu \varepsilon)\end{array}$ & $\begin{array}{c}\text { Neutral axis } \\
\text { location }(\mathbf{m m})\end{array}$ \\
\hline 1 & 85 & -27 & 193 & 69 & -31 & 248 \\
\hline 9 & 32 & -11 & 205 & 27 & -13 & 260 \\
\hline
\end{tabular}

\section{DEFLECTION MEASUREMENT}

Displacement meters were installed on the bottom of the hollow slabs to measure the midspan deflection in the different conditions. The midspan deflection of all the slabs before strengthening in condition 1 is shown in Figure 15a. The deflection of slab 5 was the maximum under the symmetrical loads. The maximum deflections were $3.9 \mathrm{~mm}$ and $2.8 \mathrm{~mm}$ for two trucks (Trucks $A+$ B) before and after strengthening, respectively. The deflection was reduced by $3 \mathrm{~mm}$ compared with that before reinforcement. The deflection for slab 1 and slab 5 were $1.5 \mathrm{~mm}$ and $2.7 \mathrm{~mm}$ before strengthening, respectively. The deflection for slab 1 and slab 5 were $1.1 \mathrm{~mm}$ and $2.2 \mathrm{~mm}$ after strengthening, respectively. Figure $15 \mathrm{~b}$ shows the midspan deflection of all the slabs after strengthening in condition 2. The maximum deflections of slab 1 were $4.6 \mathrm{~mm}$ before strengthening. After strengthening, the deflection was $3.8 \mathrm{~mm}$ for the two trucks (Trucks $A+B$ ). As expected, a certain decrease in deflection after the application of PUC reinforcement could be observed. 
Article no. 2

CIVIL

ENGINEERING JOURNAL

THE CIVIL ENGINEERING JOURNAL 2-2021

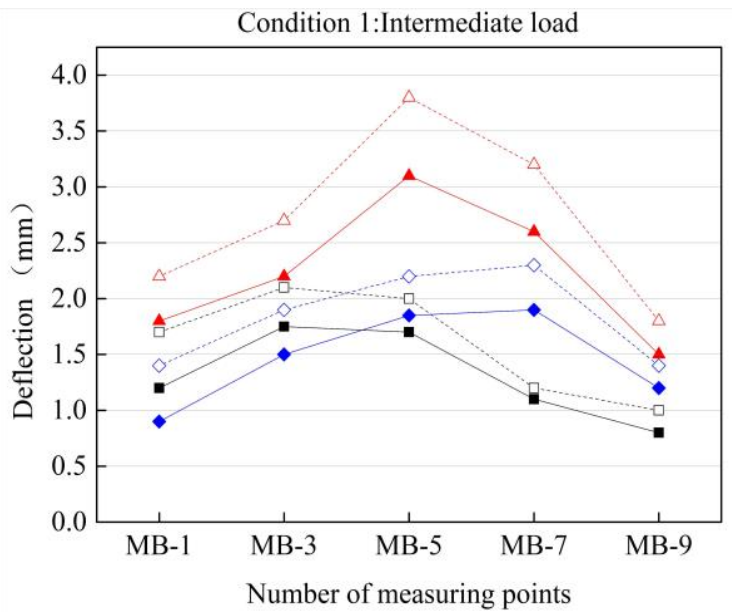

(a) Deflections in the condition 1

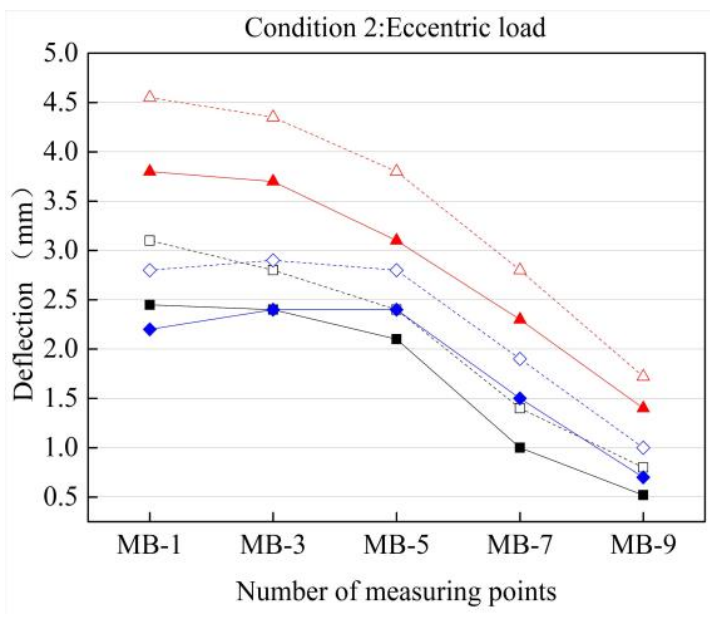

(b) Deflections in the condition 2

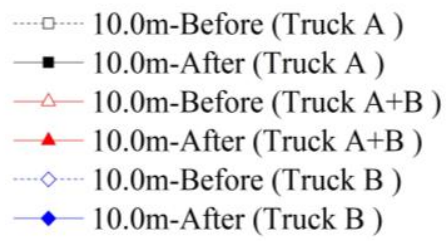

(c) Annotation explanation

Fig. 15 - Measured deflection of hollow slabs in condition 1 and condition 2

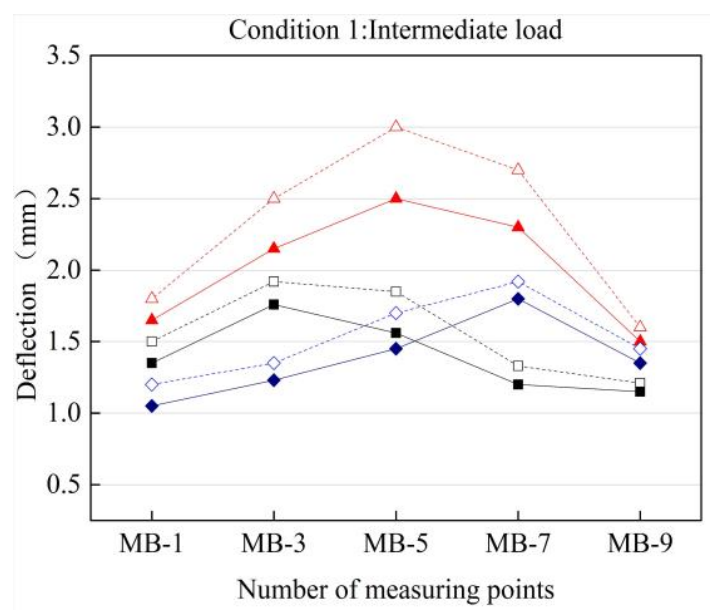

(a) Deflections in the condition 3

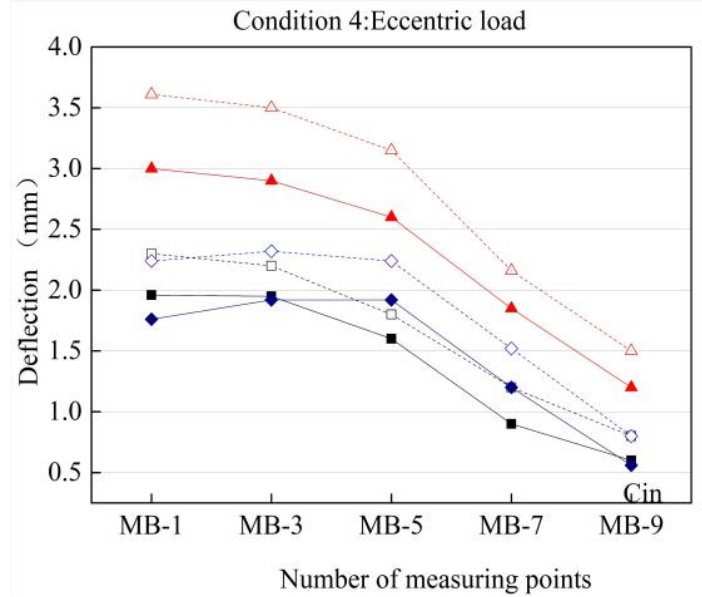

(b) Deflections in the condition 4

Fig. 16 - Measured deflection of hollow slabs in condition 1 and condition 2 


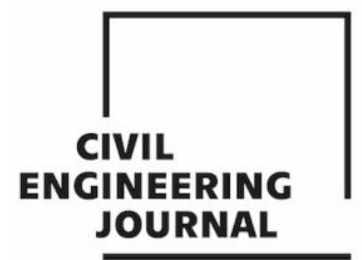

Article no. 2

THE CIVIL ENGINEERING JOURNAL 2-2021

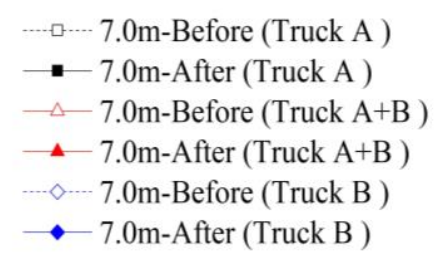

(c) Annotation Explanation

Fig. 16 - Measured deflection of hollow slabs in condition 1 and condition 2

Figure 16a and Figure 16b show the midspan deflection of all the beams before and after strengthening in condition 3 and condition 4, respectively. In condition 3, the deflections of slab 5 were $3.0 \mathrm{~mm}$ and $2.5 \mathrm{~mm}$ for the two trucks (Trucks $A+B$ ) before and after strengthening, respectively. The deflection decreased by about $0.5 \mathrm{~mm}$ after strengthening. Before strengthening, the deflections of slab 1 and slab 3 were $1.7 \mathrm{~mm}$ and $2.5 \mathrm{~mm}$, respectively. After strengthening, the deflections of slab 1 and slab 3 were $1.7 \mathrm{~mm}$ and $2.2 \mathrm{~mm}$, respectively. In condition 4 , the deflections of slab 1 were $3.7 \mathrm{~mm}$ and $3.0 \mathrm{~mm}$ for the two trucks (Trucks $A+B$ ) before and after strengthening, respectively. The deflection decreased by about $0.7 \mathrm{~mm}$ after strengthening. Before strengthening, the deflections of slab 3 and slab 5 were $3.5 \mathrm{~mm}$ and $3.2 \mathrm{~mm}$, respectively. After strengthening, the deflections of slab 1 and slab 3 were $2.2 \mathrm{~mm}$ and $2.8 \mathrm{~mm}$, respectively.

These findings represent an initially good performance, although the long-term performance will be monitored throughout the next year.

\section{CRACKS}

In the load test before retrofitting, the width of the cracks increased with the test load, but no new cracks appeared. These cracks had affected the durability of the bridge and would have further reduced the performance of the bridge if no actions were taken. In observing the development of the cracks after reinforcement, a crack (2-2 measure point) in the side slab for slab 9 was selected to be the observation crack of the load test. The width of the crack on the bottom concrete is $0.15 \mathrm{~mm}$ before strengthening. The depth from the observation location to the bottom concrete surface was $10 \mathrm{~cm}$. The width of the crack at the observation location is $0.08 \mathrm{~mm}$. Its width was unchanged for one truck (Truck $A$ ), $0.01 \mathrm{~mm}$ for two trucks (Trucks $A+B$ ) in condition 2 and closed when the trucks were moved from the deck. Furthermore, periodical inspections were conducted to observe the development of the crack. The crack was found to be stable.

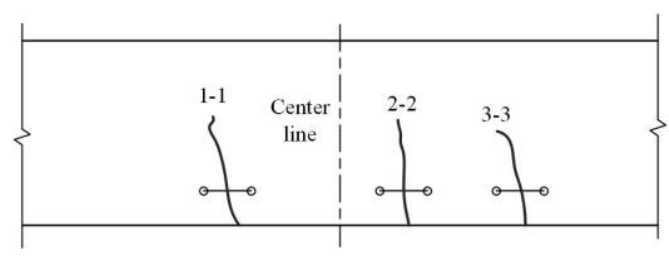

Fig. 17 - Schematic diagram of fracture observation

\section{LIVE-LOAD DISTRIBUTION FACTORS}

Many techniques are available in determining transverse live-load distribution or girder distribution factors (DFs). Khaloo et al. [20] analysed the DFs by using the finite element method 
considering four different parameters. Field testing could also provide information on live-load DFs for a given bridge type and geometry [21-23]. As the geometric size of all the hollow slabs is almost the same, the stiffness of every slab can be considered as having an equal value. The DFs can be determined from field. measurements using the following:

$$
D F_{i}=\delta_{i} / \sum \delta_{i}
$$

where $\delta_{i}$ is the maximum static deflection in the $i$ th slab, and $i=1 \sim 5$. The deflection measurements shown in Figure 18 for Pia oFa Bridge in condition 2 were used to determine the live-load DFs according to Equation (7). From the horizontal hinged plate method [24], live-load DFs that can be compared with the measured DFs Figure 18 were provided. The slab 9 deflected by $2.5 \mathrm{~mm}$ for one truck (Truck A) in condition 2. The total deflection of all of the slabs was $8.5 \mathrm{~mm}$ for a live-load DF of about 2.5/8.5 or 0.29 . The live-load DF is 0.30 using the horizontal hinged plate method. The live-load DFs depend on slabs spacing, span, girder bending stiffness and girder torsional stiffness. The slab 9 deflected by $3.8 \mathrm{~mm}$ for the two trucks (Truck $A+B$ ) in condition 2. The total deflection of all of the girders was $14.3 \mathrm{~mm}$ for a live-load DF of about 3.8/14.3 or 0.27 . The live-load DF is 0.28 using the horizontal hinged plate method. Thus, the horizontal hinged plate method is applicable for calculating the live-load DFs of T-beam bridges.

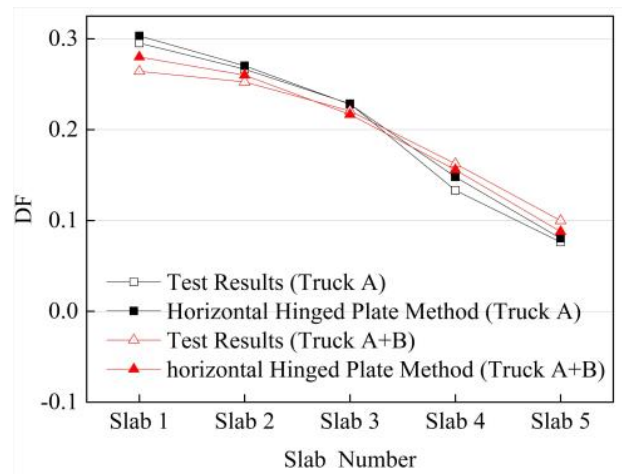

Fig. 18 - Live -load DFs calculated from test results and horizontal hinged plate method in condition 2

\section{CONCLUSION}

This paper uses an innovative method to strengthen a 25-year bridge with polyurethane cement composite material. The main construction process was described. Load tests were conducted before and after strengthening to evaluate the performance of this bridge and the effectiveness of the reinforcement method. Based on load test and analysis, the main results obtained in this study are listed below:

The blending strength of the hollow slab bridge strengthened with PUC can be determined by force equilibrium, strain compatibility and controlled failure modes. The fabricated hollow slab bridge strengthened with PUC is governed by the PUC design strength.

The maximum carrying capacity of the main girder was increased by about $20 \%$ after PUC material was poured. The main girder deflection was reduced by about $28 \%$. The width of the cracks was reduced in different degrees. Repeated load tests will be conducted to observe longterm performance. 


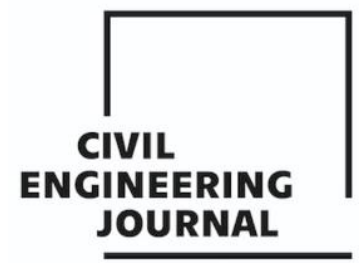

Article no. 2

THE CIVIL ENGINEERING JOURNAL 2-2021

The PUC strain deformation complies with strain coordination under the static load. The neutral axis of hollow slab migrated downwards after the PUC was poured.

The transverse connection between slabs was proven by the hinged joints. The live-load DFs of the strengthened bridge calculated by experimental results were in good agreement with the modified eccentric-pressed method.

\section{REFERENCES}

[1] Michael H Faber and Dimitri V Val and Mark G Stewart. Proof load testing for bridge assessment and upgrading[J]. Engineering Structures, 2000.

[2] Kim T H , Lee K M , Chung Y S , et al. Seismic damage assessment of reinforced concrete bridge columns[J]. Engi-neering Structures, 2005, 27(4):p.576-592.

[3] J. Campos E. Matos, J. R. Casas \& J. Figueiras. A new methodology for damage assessment of bridges through in-strumentation: application to the Sorraia River Bridge[J]. Structure and Infrastructure Engineering, 2005.

[4] G. H. Xing, T. Wu, B. Q. Liu and H. Huang, "Experimental Investigation of Reinforced Concrete TBeams Strengthened with steel Wire Mesh Embedded in Polymer Mortar Overlay",Advances in structural Engineering, vol.13, no. 1, pp. 69-79, 2010.

[5] G. Wu, Z. S. Wu, W. Yang and J. B. Jiang, "Flexural strengthening of RC beams using distributed prestressed high strength steel wire rope: theoretical analysis", Structure and Infrastructure Engineering, vol.10, no. 2, pp. 160-171, 2012.

[6] Chen W C . Some experimental investigations in the drilling of carbon fiber-reinforced plastic (CFRP) composite laminates[J]. International Journal of Machine Tools and Manufacture, 1997, 37(8):1097-1108.

[7] Wenwei W, Guo L . Experimental study and analysis of RC beams strengthened with CFRP laminates under sus-taining load[J]. International Journal of Solids and Structures, 2006, 43( 6):1372-1387.

[8] Zhang J , Zhou P , Guan C , et al. An ultra-lightweight CFRP beam-string structure[J]. Composite Structures, 2020, 257(1):113149.

[9] Dong L, Guangyuan C, Yuquan C , et al. Experimental research and numerical simulation of RC beams strength-ened with bonded steel plates[J]. ence China Technological ences, 2012, 55(012):32703277.

[10] Vincenzo Colotti Giuseppe Spadea. Shear Strength of RC Beams Strengthened with Bonded Steel or FRP Plates[J]. Journal of Structural Engineering, 2001.

[11] Hua Huang, Jianling Hou. Mechanism of Debonding Failure between Reinforced Layer with Stainless Steel Wire Mesh and Polymer Mortar and RC Structures[J]. Advanced Materials Research, 2010:163-167.

[12] Hua Huang, Boquan Liu, Kailin Xi. Interfacial tensile bond behavior of permeable polymer mortar to concrete[J]. Construction and Building Materials, 2016, 212:210-221.

[13] L. Guiwei and O.Hisanori,"A foundational study on static mechanical characteristics of the super lightweight and high strength material using fly-ash",Journal of the Society of Materials Science, vol.55, no. 8, pp. 738-745, 2006.

[14] K. Haleem, L. Guiwei and Y. Wenyong, "Experimental study to investigate mechanical properties of newmaterial polyurethane-cement composite (PUC)",Construction and Building Materials, vol. 50, no. 15, pp. 200-208, 2014.

[15] K. Haleem, Z.Lianzhenand L. Guiwei,"An experimental study on strengthening reinforced concrete Tbeams using new material poly-urethane-cement (PUC)", Construction and Building Materials, vol.40, pp. 104-117, 2013.

[16] Ministry of Communications of China, Design Code of Highway Reinforced Concrete and Prestressed Concrete Bridge (JTJ023-85). Beijing: China Communication Press, 1985.

[17] Ministry of Construction of China, Design Code of Concrete Structures (GB50010). Beijing: China Building Industry Press, 2010.

[18] Chappuis J L , Veldman M S, Taylor H S . Surgical instrumentation and method for forming a passage in bone hav-ing an enlarged cross-sectional portion: US. 
[19] Yang B , Chen S H . Methods for Calculating Shear Capacity on Oblique Section of Bending Members Strengthened with Enlarged Section[J]. Journal of Highway \& Transportation Research \& Development, 2016, 11(3):71-78.

[20] A. Khaloo, and H.Mirzabozorg, "Load Distribution Factors in Simply Supported Skew Bridges", Journal of Bridge Engineering, vol.8, no. 4, pp. 241-244, 2003.

[21] M. Schwarz, and J.Laman, "Response of Prestressed Concrete I-Girder Bridges to Live Load", Journal of Bridge Engineering, vol.1, no. 1, pp. 1-8, 2001.

[22] S. Kim, and A.Nowak, "Load Distribution and Impact Factors for I-Girder Bridges", Journal of Bridge Engineering, vol.3, no. 97, pp. 97-104, 1997.

[23] Seo J, Kidd B . Parametric study of deteriorating precast concrete double-tee girder bridges using computational models[J]. Engineering Structures, 2021, 230(3):111714.

[24] Ministry of Communications of China, General Specification for Highway Bridge and Culvert Design (JTG D60). Beijing: China Communication Press, 2015. 